\title{
Certify it! Breast Cancer Units in Europe
}

\author{
Serban-Dan Costa \\ Universitätsfrauenklinik, Otto-von-Guericke-Universität Magdeburg, Germany
}

The focus on breast centers in the current issue of BREAST CARE tries to offer an overview on the efforts of physicians to improve treatment of breast cancer by development and operation of Breast Units in different countries of the European Union. We must conclude that it is still an ongoing effort because every country interprets and implements the guidelines of the European Parliament regarding certification of Breast Units differently [1]. The development of multidisciplinary centers is based on the following premises:

1. Minimum numbers: treatment and diagnosis of many patients with the same disease leads to more experience compared to someone who treats fewer patients.

2. Interdisciplinarity: breast cancer is a complex disease with several aspects that require interdisciplinary work.

3. Diagnosis: breast cancer and its precursor lesions need to be diagnosed as early as possible in order to enable improvement of disease process and survival.

4. Equal opportunities: every patient in Europe should be able to get the same diagnosis and treatment opportunities, independently of the country of origin. Differences and errors can be detected and improved through benchmarking.

5. Control: Breast Units should be developed by specific guidelines and should undergo sporadic controls by independent organizations. Successful audits should be documented by certificates.

6. Costs: quality management and quality control enable better structures, avoid redundancy and lower costs.

In some European countries, especially in university centers, the idea of superspecialization and development of centers was introduced as early as the 1970s and 1980s. Examples are the 'Instituto Nationale dei Tumori' in Milan, Italy, and its offspring, the European School of Oncology (its leading specialists are Umberto Veronesi and Gianni Bonadonna) and the Breast Center at the Women's University Hospital in Heidelberg, Germany (founder Fred Kubli). For decades, such units have clinicians at work dealing most of the time with benign and malignant breast disease. Early detection, diagnosis and multimodal therapy (imaging and invasive diagnostics, breast surgery, systemic therapy and radiation) are hereby interdisciplinary and under one roof.

The term 'Breast Unit' is new and the idea of building such centers was pushed in Europe by the work of the consortium EUSOMA (European Society of Mastology), which in 2000 published a manuscript in the European Journal of Cancer (EJC) [2]. In this publication, the preconditions or rather the numbers (i.e. 'minimum numbers') were mentioned that are required to develop and build a Breast Unit. Basic data of such an 'Exemplary Breast Unit based on EUSOMA Criteria' includes the number of patients diagnosed and treated by surgery and systemic therapy per physician per center [2]. Several details were based on the personal experience and ideas of the authors and a few points were based on scientific data. In the same issue of the EJC, a remarkable editorial was published by M.J. Silverstein [3], a world-famous breast surgeon based in California. Unfortunately, his critique found little acknowledgement back then and still today.

It would be worth revisiting his comments and critical questions before analyzing the actual state of breast units 9 years after the publication of both papers:

'Who should tell the patient that she has breast cancer? - Who should discuss and decide adjuvant therapy? - Must a radiologist do 5,000 mammograms a year? Would 4,000 be sufficient? - Must a surgeon do 50 cases per year? What if he/she does 100 , but does them all wrong? - How will new technology, like sentinel node biopsy, be incorporated? Will it be mandated throughout the system? Will some centers use it and others not? - One of my colleagues stated that the major defect with this protocol was that it focused on the structure of a multidisciplinary breast service, but not on the goals. - The document as written calls for protocols for the management of all stages of disease. How will this be done? Consider DCIS as an example. In 1997, a consensus conference regarding the pathology of the disease was held in Philadelphia. No agreement could be reached on a unified classification for the disease.

\section{KARGER}

Fax +497614520714

Information@Karger.de

www.karger.com (c) 2009 S. Karger GmbH, Freiburg

Accessible online at:

www.karger.com/brc
Prof. Dr.Dr.h.c. Serban-Dan Costa

Universitätsfrauenklinik, Otto-von-Guericke-Universität Magdeburg

Gerhart-Hauptmann-Straße 35

39108 Magdeburg, Germany

Tel. +49 391 6717-310, Fax -311

Serban-Dan.Costa@med.ovgu.de 
Two years later, a second consensus conference was held, this time to discuss treatment. Again, no uniform agreement could be reached. Because breast cancer is a heterogeneous group of lesions, as the current cliché goes, written protocols for the management of all stages will be extremely challenging.'

When he wrote the editorial, Silverstein was a physician who 20 years before (in 1979) had established and run one of the first breast units in the world in Van Nuys, California and subsequently opened and headed another breast unit at the University of Southern California in 1998. He acknowledged the limitations of implementing the 'American Breast Units' in Europe due to differences in professional policies and structure, but you have here the voice of a very experienced person who knows what he is talking about and doesn't mince words.

If you want to sum up Silverstein's comments in one sentence: he had apprehensions regarding a rigid theoretical concept that does not realign based on results, in addition to having specific local circumstances not taken into account. The objectives and results should drive the concept and structure, not the other way around.

In daily practice every physician sees that the main objective for the patients is overall survival and that to achieve it, they are ready to endure mutilating surgeries, debilitating side effects of therapies, and severe restrictions in quality of life. Nonetheless, physicians often discuss other objectives like the rate of breast conserving surgery, sentinel node biopsy, breast reconstruction and much more. However, these should not be the main focus.

Any good and reliable physician who treats patients with breast cancer should keep those objectives in mind. But, the point in question in this issue of BREAST CARE is how we should proceed in order to reach the objectives and if our system, with the development of breast units, is the answer to the numerous challenges that breast disease brings.

\section{Minimal Numbers - Center Volume and Interdisciplinarity}

The authors Scharl and Göhring discuss the correlation between minimal numbers and course of disease [4]. For the criterion of minimal numbers, it is important to know which parameters are being used. There is a correlation between the number of operations and morbidity/mortality in 'big surgery' (organ transplantation, aorto-coronary bypass, pancreaticoduodenenctomy), but these results cannot be transposed to the treatment of breast cancer because in most of the cases, small (and standardized) surgical interventions are performed, which by definition carry a very low morbidity. Moreover, other therapies (chemotherapy, endocrine therapy, radiotherapy) play an important role in breast cancer.

Some authors could show that physicians that treat many patients often use more systemic therapies and thereby improve the overall chances of survival of their patients. Establishing a cut-off value (number of patients per year) to be used to define a breast cancer specialist is not an easy task because in the literature, different patient collectives were compared.
Data from different regions of Great Britain showed that the survival of patients is improved if they were treated by physicians that treat more than 30 patients per year $[5,6]$. In the USA and in Asia, it has been shown that the number of patients per unit correlates with survival, but different numbers are given that would define a 'high', 'medium' or 'low' volume center [7, 8]. Finally, Roohan et al. [9] showed that in the New York area, the disease course is better if more than 150 patients per year are treated in a hospital. A linear correlation between the number of patients per physician or treatment unit and disease course could not be proven by anyone.

It is not only the number of patients in the hospital that is an important determining factor for the disease course, but also the infrastructure. The best results are achieved when everything is available under one roof: preoperative diagnosis, on-site radiotherapy, research activity, teaching status [10].

All in all, the analysis of Scharl and Göhring clearly shows that patients in high-volume hospitals are treated according to international guidelines more often and the treatment is associated with lower morbidity and mortality, thereby showing that it is crucial how therapy is primarily planned. If therapy decisions are made and carried out by an interdisciplinary team, it is possible to achieve the best results. Breast surgery plays a lesser role compared to the consistent and individualized use of multimodal therapies (systemic therapy, radiotherapy).

\section{Equal Opportunities and Control - Breast Units in Europe}

Taran et al. [11] analyzed the significance and the structure of breast units in all European countries respective of the certification process. The authors developed a simple questionnaire consisting of 5 questions regarding existence and the number of Breast Units, and the certification process. It was sent to national cancer organizations, study groups, breast cancer organizations, and breast specialists per telephone and per e-mail. Despite friendly insistence, the response rate of the questionnaire was catastrophic: only $8 \%$ of the persons contacted by phone and $5 \%$ of the persons contacted by e-mail answered the questionnaire.

The authors have however managed to get information from 16 countries that have built Breast Units and registered them for the project SenoNetwork. Detailed information on the planning of Breast Units and the certification process was obtained from 9 countries. In most of the countries the EUSOMA criteria are used and the Breast Units cover regions with a minimum of 200,000-300,000 inhabitants. Certification is carried out by public organizations in more than half of the countries $(57 \%)$ and in the others by private companies. The certification process, as well as the length of time between controls, vary greatly among the European countries. It seems that the development of Breast Units and their certification is not a high priority in most European countries.

It is that much more astonishing to see how much manpower, time and financial complexity are used to build Breast 
Units in Austria and Germany. The status of breast cancer care in Austria was analyzed by S. Pöstlberger [12]. Here, the objectives of center development are clearly defined: convergence of care, enhancement of quality of care and a significant benefit for women with breast cancer. In Austria, the EUSOMA guidelines regarding minimal numbers and infrastructure play a role. Because of special infrastructural conditions, a cooperation model is established between Breast Health Centers with more than 100 patients with primary breast cancer and affiliated centers with more than 30 patients per year. With the way this model is set-up and the cooperation between both center types, the objective is to provide equal treatment regardless of where patients receive their treatment. Thus, a comprehensive state-of-the-art supply is established. How well this system works will be analyzed in a stepwise concept in 2010, 2013 and 2016.

The special thing about the Austrian system is that it was established together with political affiliates and health insurance companies and it also takes into account region-specific factors. It shows vision and wisdom to integrate smaller hospitals in the concept not only because patients have developed a special confidence in physicians and clinics in their region over the years, but in case of disease they will not have to move away from their familiar environment for their treatment. Moreover, the system 'live and let live' has better chances because smaller clinics do not have to fear for their existence.

We hope that many colleagues from Europe will read the article from Pöstlberger and get introduced to the Austrian model. Even if the health systems in Europe are very heterogenous, I personally can imagine that this model would work for several countries.

In Germany, there is a special situation and a comparison with other countries is impossible. There is no uniform cancer registry. The reasons are unclear, the fact is, however, that we do not know the incidence of breast cancer in our country and we do not know if there are regional differences. The only available data are derived from the cancer registries in Bremen, Saarland and the Bavarian Tumor Center. It is possible to hear opinion leaders start their keynote lectures about breast cancer with statements like '45,000-65,000 newly diagnosed cases per year'. If the treatment costs for one breast cancer patient is at least $50,000 €$, we are talking about a difference of one billion $€$ per year! Such costs are relevant even for the health care system of such a wealthy country as Germany, but they do not seem to lead to the clarification of the situation. Clarification would mean to establish a wellconducted cancer registry, in which the data are continuously analyzed by epidemiologists.

The absence of data does not prevent experts in politics and health insurance companies as well as individual scientists from expressing their opinions and approximations of the numbers in 'advisory boards' [13]. Coincidentally, it was found that breast cancer treatment in Germany is different within its regions and is worse compared to other European countries.
Why? Because they determined how many women die from breast cancer every year from the civil registry offices and the federal statistics office. A correlation to incidence and prevalence could not be established and therefore such affirmations are taken from thin air. But...it is expert thin air!

Nevertheless, there were two actions described by Albert and colleagues [14] that seem appropriate: the establishment and implementation of guidelines for the treatment of breast cancer and the comprehensive development of breast centers and their certification. Under the patronage of the German Cancer Society and taking into consideration the criteria of the Association of Scientific Medical Societies (AWMF) multidisciplinary S3 guidelines were developed and published $[15,16]$. This manual is widely distributed and used by most physicians who treat breast cancer.

The German Cancer Society and the German Society of Senology have established criteria that rely on the $\mathrm{S} 3$ guidelines and the EUSOMA criteria in order to establish and develop multidisciplinary breast units. Once the criteria are fulfilled and quality management is available, Breast Units are certified and undergo yearly audits. The certification is provided by a private company 'OnkoZert ${ }^{\circledR}$, and in the federal state with the largest population, North Rhine-Westphalia, through the Chamber of Medical Care Providers. Meanwhile, there are 181 certified Breast Units in Germany and according to an analysis of OnkoZert $60 \%$ of the patients are treated in certified Breast Units.

It seems that after the introduction of Breast Units, there has been conformity of diagnosis establishment and treatment of breast cancer. For example, Albert et al. [14] cited the rise of preoperative diagnosis from $58 \%$ in 2003 to $88 \%$ in 2008 and the use of endocrine therapy ( $27 \%$ in 2003 vs. $93 \%$ in 2008). A problem is that parameters like these are available, in absence of the relevant survival data of patients. A further problem, which is probably not resolvable, is that there are no start data (data before the establishment of Breast Units) to compare to the relapse-free and overall survival of breast cancer patients.

If this is an improvement of the treatment quality or just a better documentation under the pressure of the certification process cannot clearly be determined. Fact is that the annual certification of Breast Units costs a lot of time and money. There is no scientific proof that the extensive documentation and/or the short, yearly time frame of re-certification is necessary for ensuring treatment quality.

The objective of the establishment of Breast Units in Germany was the centralization of diagnosis and therapy that was previously performed in many clinics and the ambulatory sector. This objective was only partly achieved because in many cases the criteria for certification of a Breast Unit were met through aggregation of several ambulatory clinics and therefore patients are treated by the same physicians as before but now... certified. The question of what exactly the certification achieved in terms of more uniform and improved diagnosis 
and therapy - is a matter of debate. Taking into account the right of physician choice ensured by the constitution of Germany, it cannot be expected that further centralization will take place in the near future.

\section{Do Breast Units Lead to a Better Cost-Benefit-Ratio for the Diagnosis and Treatment of Breast Cancer?}

If you take examples from other areas of the economy, centralization should succeed in improved business cycles and fewer redundancies (in medicine, this would be equivalent to a lower rate of test repetition, faster healing and more patients surviving) leading to higher benefits and lower costs. This sounds logical as long as we put medicine on a level with economics. Of course there are economic aspects in medicine, however, this should not lead us to use economic measures in the treatment of patients. For example, the production of a screw should be considered differently from the removal of a nodule in the breast. Both are repetitive tasks, however, a screw will come out the same from the machine every time, whereas even small surgical interventions sometimes do not turn out as expected and the remainder of the course is not entirely predictable. The illusion that it is predictable is not fostered by those making the intervention, the physicians, but by outsiders who may understand economics and management but don't understand medicine.

The establishment of Breast Units and the continuous audits for the certification processes entail a huge documentation and financial effort. We must give credit to the working group of M.W. Beckmann from Erlangen who was the first in Germany to ask the question about the cost/benefit ratio pertaining to the development and functioning of Breast Units [17].

Beckmann et al. [17] show that certain parameters, e.g. the rate of breast conserving therapies, determination of hormone receptors in the tumor, sentinel node biopsies, and study participation, can lead to lower mortality and morbidity but will raise costs. Diagnosis and therapy are increasingly performed according to guidelines if there are specialists at work. But this means higher costs compared to not doing hormone receptor determination and foregoing axillary lymph node marking with radioactive technetium to localize the sentinel lymph node. To optimize courses, introduce quality management, and participate in clinical studies we need more infrastructure, manpower, and money. Based on the calculations by Beckmann et al. [17] we would need about $1,300 €$ more per breast cancer patient and according to others about $1,650 €$ more than what is currently covered the insurance companies in Germany - which is 3,095.96€ per patient [18].

In a conversation with a high-ranking insurance company representative in Germany, I learned that insurance companies are willing to finance the product or service, but not the process. Clearly, this means that everything we do to establish the Breast Unit and maintain the certification in order to improve diagnosis and treatment for breast cancer will not be remunerated. According to the insurance companies, the infrastructure, manpower, and everything else that belongs to good treatment should be paid for by someone else. - Who that could be no one knows.

\section{Summary and Forecast}

The establishment of breast centers in Europe seems to be a logical procedure to improve the prognosis of breast cancer. All analyses have shown that due to the centralization, a certain grade of specialization is achieved and the treatment results are improved. To define a minimum number of patients per center or per physician is still not easy, even 9 years after the publication of the EUSOMA criteria. Perhaps it is more of an intrinsic problem of cut-off values per se, which cannot be scientifically validated in medicine. In different European countries, the need for and structure of Breast Units are viewed differently, therefore we are still far away from a standard treatment and equal opportunity for all breast cancer patients in Europe. Perhaps additional political pressure and money are needed to develop Breast Units in all European countries. Without additional reimbursements from insurance companies, the present efforts to concentrate and centralize diagnosis and treatment of breast cancer are endangered.

Despite the limitations described in all articles in the present issue, the establishment of Breast Units in some places in Europe is, in my opinion, a gleam of hope for breast cancer patients. If we manage to reduce the bureaucratic overload and costs, to document less but focus on more important things, and if a real benchmarking can be achieved, then we can talk of real progress in Europe.

\section{References}

1 Bericht über Brustkrebs in der Europäischen Union (2002/2279(INI)). Ausschuss für die Rechte der Frau und Chancengleichheit. Berichterstatterin: Karin Jöns. Europäisches Parlament. 7. Mai 2003

$\checkmark 2$ The EUSOMA Position Paper on the requirements of a specialist breast unit. Eur J Cancer 2000;36: 2288-2293.

3 Silverstein MJ: State-of-the-art breast units - a possibility or a fantasy? A comment from the US. Eur J Cancer 2000;36:2283-2285.
4 Scharl A, Göhring U: Does center volume correlate with survival from breast cancer? Breast Care 2009;4:237-244.

5 Mikeljevic JS, Haward RA, Johnston C, Sainsbury R, Forman D: Surgeon workload and survival from breast cancer. Br J Cancer 2003;89:487-491.

6 Gillis CR, Hole DJ: Survival outcome and care by specialist surgeons in breast cancer. BMJ 1996;312: 145-148.

7 Skinner KA, Helsper JT, Deapen D, Ye W, Sposto R: Breast cancer: do specialists make a difference? Ann Surg Oncol 2003;10:606-615.
8 Chen CS, Liu TC, Lin HC, Lien YC: Does high surgeon and hospital surgical volume raise the fiveyear survival rate for breast cancer? A populationbased study. Breast Cancer Res Treat 2008;110: 349-356.

$\checkmark 9$ Roohan PJ, Bickell NA, Baptiste MS, Therriault GD, Ferrara EP, Siu AL: Hospital volume differences and five-year survival from breast cancer. Am J Public Health 1998;88:454-457. 
10 Hébert-Croteau N, Brisson J, Lemaire J, Latreille $\mathrm{J}$, Pineault R: Investigating the correlation between hospital of primary treatment and the survival of women with breast cancer. Cancer 2005;104:13431348.

11 Taran A, Eggemann H: Breast units in Europe Certification in nine European countries nine years after the European Society of Mastology position paper. Breast Care 2009:4:219-222.

12 Pöstlberger S: Breast centers in Austria. Breast Care 2009;4:231-236.
13 Sachverständigenrat für die konzertierte Aktion im Gesundheitswesen: Bedarfsgerechtigkeit und Wirtschaftlichkeit. Bd. I; Bd. II. 2001; 11:45-47,96.

14 Albert US, Wagner U, Kalder M: Breast centers in Germany. Breast Care 2009;4:225-230.

15 Lorenz W, Ollenschläger G, Geraedts M, Gerlach F, Gangjour A, Helou A, Kirchner H, Koller M, Lauterbach W, Reinauer H, Sitter H, Thomeczek C: Das Leitlinien Manual: Entwicklung und Implementierung von Leitlinien in der Medizin. ZaeFQ 2001;95:1-84.
16 Deutsche Krebsgesellschaft, Kreienberg R. (Hrsg.): Interdisziplinäre S3-Leitlinie für die Diagnostik, Therapie und Nachsorge des Mammakarzinoms. München, Zuckschwerdt, 2008.

17 Beckmann MW, Bani MR, Loehberg CR, Hildebrandt T, Schrauder MG, Wagner S, Fasching PA, Lux MP : Are certified breast centers cost-effective? Breast Care 2009;4:245-250.

18 Köckemann M, Lillteicher F: Entgeltverhandlungen 2007 - folgt das Geld der Qualität? Die bislang ausgebliebene Finanzierung zusätzlicher Strukturqualität von Brustzentren in NordrheinWestfalen. Krankenhaus 2007;5:439-445. 